\title{
Thermal plasticity of wing size and shape in Drosophila melanogaster, $D$. simulans and their hybrids
}

\author{
V. Trotta ${ }^{1, *}$, C. Pertoldi ${ }^{2,3}$, A. Rudoy $^{1}$, T. Manenti ${ }^{1}$, S. Cavicchi ${ }^{1}$, D. Guerra ${ }^{1}$ \\ ${ }^{1}$ Alma Mater Studiorum, Università di Bologna, Dipartimento di Biologia Evoluzionistica Sperimentale, Via Selmi 3, \\ 40126 Bologna, Italy \\ ${ }^{2}$ Department of Biological Sciences, Ecology and Genetics, Aarhus University, Ny Munkegade, Building 1540, \\ 8000 Århus C, Denmark
}

${ }^{3}$ Mammal Research Institute, Polish Academy of Sciences, Waszkiewicza 1c, 17-230 Białowieża, Poland

\begin{abstract}
Populations of Drosophila melanogaster, as well as of other Drosophila species, show body size differences according to their geographic origin. Thermal selection is considered to be the most likely cause explaining these differences. We investigated wing size, wing shape and their relationship in 3 different geographic populations of $D$. melanogaster, 1 population of $D$. simulans, and their interspecific hybrids grown at $18,21,25$ and $28^{\circ} \mathrm{C}$. The aim was to explore how the past adaptive history of 2 related species, or populations of the same species, modulates the plastic response to the environment. The wing size plasticity of hybrids between the temperate $D$. simulans (Bologna) and the 2 tropical D. melanogaster populations (Belém and Rio de Janeiro) was higher than that of parental species, probably as a side effect of a decanalized and compromised development at higher temperatures. The wing size plasticity of Bologna hybrids was the same as the parents, suggesting that the 2 species are subjected to the same plasticity selection. Wing shape was typical of each species, population and temperature. Shape differences increased in hybrids at higher temperatures as a consequence of developmental perturbation. The allometric relationship between size and shape changed among temperatures and among species, suggesting that the wing development is differently regulated in the 2 species and can be altered by natural selection. The allometry changed between populations of different geographic origin of $D$. melanogaster, but was similar in the 2 species that shared the same selective environment. Two species would have been subjected to the same plasticity selection, so the breakdown of the plastic response is avoided in hybrids. As a whole, these data suggest that thermal plasticity is a trait under selection and that similar mechanisms are at work in different species.
\end{abstract}

KEY WORDS: Drosophila $\cdot$ Hybrids $\cdot$ Development $\cdot$ Evolutionary constraints $\cdot$ Phenotypic plasticity

\section{INTRODUCTION}

The global surface temperature has increased by an unprecedented $0.8^{\circ} \mathrm{C}$ over the past $100 \mathrm{yr}$ and by $0.2^{\circ} \mathrm{C}$ per decade in the last 30 yr (Hansen et al. 2006, Serreze 2010). At the moment, predictions about the ability of organisms to respond to climate change by plastic responses and/or by adaptation (evolutionary responses) are the most challenging and exciting fields in evolution- ary biology. Phenotypic traits affecting life history (i.e. all the events that characterise the whole life cycle of an organism; Peters 1983) are grouped together and called life history traits. Body size is a pivotal trait, as other life history traits such as metabolic rate, energy requirements and reproductive success are directly affected by body size (Schmidt-Nielsen 1983, Calder 1984).

In Drosophila there is a strong correlation between body size (often measured as wing size) and fitness (Roff 
1992). Laboratory experiments have shown that there is a positive relationship between body size and fertility, longevity, mating success and lifespan (Robertson 1957, Tantawy \& Vetukhiv 1960, Partridge \& Farquhar 1983, Wilkinson 1987) in non-stressful environments.

Drosophila melanogaster, as well as other Drosophila species, has been extensively used to describe the pattern of geographical variation in body size. Comparison among natural populations showed that body size increases with latitude and altitude and, most importantly, that part of the observed variation is of genetic origin (Reed \& Reed 1948 Partridge \& French 1996). Long-term selections for temperature in the laboratory resulted in divergent body sizes, with more larger flies at colder temperatures as in the wild (Anderson 1973, Cavicchi et al. 1985, 1989, Partridge et al. 1994).

Plasticity-the ability of an organism to react to internal or external environmental inputs with a change in form, state, movement or rate of activity (West-Eberhard 2003) - is becoming more important in conservation biology because selective pressures acting on populations are much higher than they were in the pre-industrialized world. Species must adjust to an environment that changes continuously, often towards extreme conditions. Studies on phenotypic plasticity demonstrate that the plastic responses are heritable and subjected to selection, and that the heritability and effectiveness of selection depend on the range of environmental conditions where selection occurs (Stearns 1989, Scheiner \& Lyman 1991, Scheiner 1993, de Jong 1995, Price et al. 2003). Since both thermal plasticity and thermal selection act in the same direction on Drosophila body size, it is reasonable to suppose that the plastic response is adaptive (West-Eberhard 2005, Trotta et al. 2006).

Previous studies of wing shape have revealed significant interpopulation differentiation within Drosophila species (e.g. Imasheva et al. 1995, Haas \& Tolley 1998, Griffiths, Schiffer \& Hoffmann 2005), as well as phenotypic plasticity across developmental temperatures and thermal evolution in the laboratory (Cavicchi et al. 1985, 1991, Santos et al. 2004). Wing shape can be analyzed using geometric morphometric approaches, which precisely separate morphological variation (i.e. variation in form) into size (a 1-dimensional trait) and shape (an inherently multidimensional space), which can be evaluated by using the Procrustes method to obtain coordinates of shape by removing the effects of size (Klingenberg et al. 2002). Allometry is defined as shape changes associated with size changes (Penin et al. 2002) and has been shown to occur in Drosophila wings.

In the present study, we investigated wing size and shape of 3 different populations of Drosophila melanogaster, 1 population of $D$. simulans, and their interspecific hybrids. Interspecific hybrids often show reduced vitality and/or fertility. The difference between closely related species may depend on either minor changes at many genes (Charlesworth et al. 1982) or on a wide genetic (and developmental) reorganization (Carson \& Templeton 1984).

Different kinds of interaction may cause hybrid disorder: aminoacidic differences may produce non-functional proteins (Rawson \& Burton 2002); some posttranscriptional pathways may be destroyed (Braidotti \& Barlow 1997); or some genes may be deregulated and therefore under- or over-expressed (Michalak \& Noor 2003, Ranz et al. 2004). Interspecific Drosophila hybrids show different kinds of morphological abnormalities which are strongly influenced by rearing temperature (Sturtevant 1920). Hybrids often have atrophic gonads (Lachaise et al. 1986) and, as a consequence, they are sterile. The abnormalities reflect deleterious genetic interactions principally due to independent and uncoordinated changes in the 2 parental genetic pools accumulated in the absence of genetic flow (Dobzhansky 1936, Muller 1942) and to differences in gene expression (Orr et al. 1997, Sucena et al. 2003, Ranz et al. 2004).

Drosophila melanogaster and D. simulans are morphologically similar, cosmopolitan and human commensal species, but they differ in traits such as courtship behaviour, genital morphology, ecophysiology, DNA and protein polymorphisms (Capy \& Gibert 2004), and they rarely cross in the wild. In the laboratory, sterile unisexual hybrid progeny may be obtained, the sex being that of the $D$. melanogaster parent.

With the aim to provide insight into the evolution of the norm of reaction, we explored how the past adaptive history of 2 related species, as well of different geographic populations of the same species, affects the plastic response to the environment (temperature). In particular, the response of interspecific hybrids would reveal if the same adaptive strategies are at work in 2 different species. We also investigated wing allometry (i.e. the relationship between wing size and shape) and its plasticity in both parental species and hybrids, as it reflects growth developmental patterns and the interactions between species (or populations) and local climatic conditions.

\section{MATERIALS AND METHODS}

\subsection{Populations}

Three populations of Drosophila melanogaster (2 tropical and 1 temperate), and 1 temperate population of $D$. simulans were used. The temperate populations came from Bologna, Italy, collected in the same place in August 2008. Of the 2 tropical populations, one 
came from Belém, Brazil (collected in 2002) and the other from Rio de Janeiro, Brazil (collected in 2004). These populations yielded about 20 generations per year in the laboratory. All populations were founded from 20 to 30 wild-collected fertilized females and kept in mass culture on standard medium at $18^{\circ} \mathrm{C}$ until September 2008, when the experiment started.

Though it was found that the past selective history does not change over the course of a few years (Capy et al. 1993), laboratory rearing can produce inbreeding and drift that can affect some life history traits (Matos \& Avelar 2001). Nevertheless, we found that adaptive differences in some life history traits among natural populations persist in spite of laboratory adaptation or inbreeding effects; other life history traits change in only their mean values and not their plastic response over a thermal range (see Trotta et al. 2007).

\subsection{Experimental procedures}

To avoid maternal effects, flies of each species and population were allowed to oviposit for $1 \mathrm{~d}$ at a constant temperature of $25^{\circ} \mathrm{C}$ and at an optimal density (about 50 individuals in $60 \mathrm{ml}$ vials containing $10 \mathrm{ml}$ of food) for 1 generation. The emerging flies were transferred into new vials ( 7 females and 7 males per vial were used as parents, 3 vials for each population) with food (vials were smeared with abundant yeast) and maintained until adult emergence at different constant temperatures: $18,21,25$ and $28^{\circ} \mathrm{C}$.

Drosophila melanogaster virgin females of a given population were also crossed with $D$. simulans males, at a ratio of 20:30; all the offspring of these crosses consisted of hybrid females. To obtain hybrid progeny, 3 vials for each cross were also maintained at each experimental temperature under the same conditions as described above.

\subsection{Wing measurements}

Since all hybrid progenies were female, only females were considered in all groups. About 30 females per population and temperature were randomly chosen; the right wing of each fly was dissected, dehydrated in ethanol and mounted on glass in lactic acid/ethanol (6:5). All wings were photographed using a digital camera connected to a dissecting microscope, and photos were stored directly on a computer. From each wing, 11 landmark coordinates were recorded (Fig. 1) using ImageJ software.

\subsection{Procrustes superimposition}

After the landmark coordinates were recorded, all wing configurations were superimposed onto a consensus configuration (the overall mean configuration) using the Procrustes generalized least square procedure (Rohlf \& Slice 1990, Rohlf \& Marcus 1993, Bookstein 1991, Dryden \& Mardia 1998). The new coordinates, or Procrustes coordinates, are amenable to standard multivariate analyses; since there are 4 eigenvalues that are zero in the Procrustes fit, generalised inverses or principal component scores can be used.

\subsection{Size variation}

The size of an individual wing was estimated by the centroid size of its landmark configuration (Slice et al. 1996). The effects of species (i.e. Drosophila melanogaster, D. simulans and hybrids), temperature and population on wing size were appraised by applying a mixed model ANOVA to centroid size including species and temperature as main fixed effects, and population nested within species as a random effect.

\subsection{Shape variation}

We tested for shape variation among species, temperatures and populations by applying a multivariate ANOVA (MANOVA) to the scores of a principal component analysis (PCA) performed on the Procrustes coordinates, similar to the ANOVA used for the wing centroid size.

A discriminant analysis combined with a canonical variate analysis considering species and temperature as independent factors was also performed. This approach allows optimal visualization of the relative position of the different populations in the multivariate statistical space by maximizing the among-line variation.

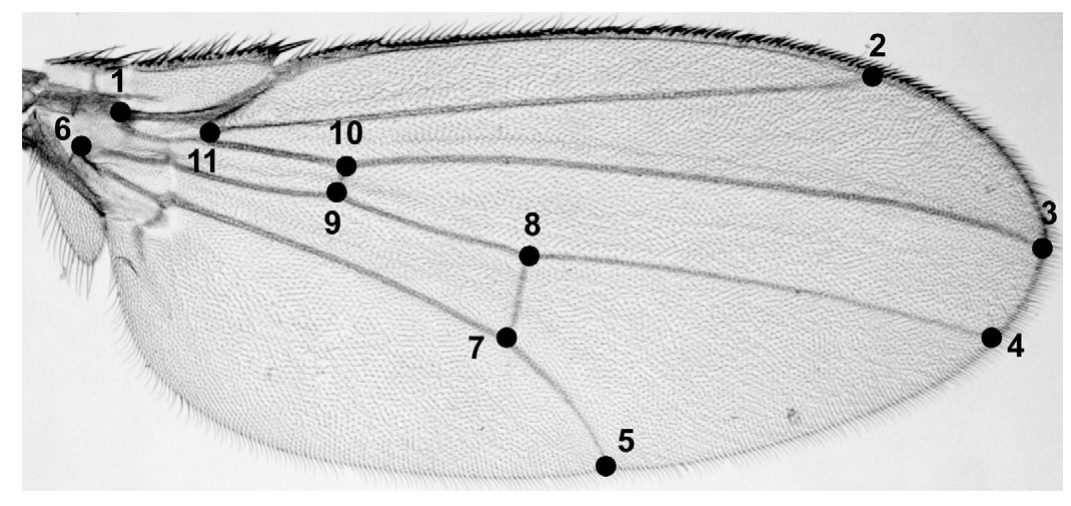

Fig. 1. Drosophila melanogaster. Wing landmarks used to analyze size and shape 
To test for size effects on shape variation, allometric corrections were done by multivariate regression of the PC scores of the Procrustes coordinates (dependent variables) on centroid size (independent variable).

The Procrustes superimposition was done using PAST version 1.90 (Hammer et al. 2001, http://folk.uio.no/ ohammer/past); all analyses in the present study were performed with R 2.9.0 (R Core Development Team 2005).

\section{RESULTS}

\subsection{Morphological abnormalities}

Interspecific hybrids at all temperatures showed morphological abnormalities, which reflects a decanalized development. Deformed individuals typically showed curly, bubbled and crumpled wings. All hybrid lines (Fig. 2) showed similar and positive temperaturedependent rates of deformations $\left(\chi^{2}\right.$ test, $\chi^{2}=3.4, \mathrm{df}=6$, $\mathrm{p}=0.7563)$.

\subsection{Wing size variation}

Mean values of wing centroid size of females of the 3 Drosophila melanogaster populations, the $D$. simulans population and their hybrids at the 4 experimental temperatures are shown in Fig. 3a. As expected, the wing size of the $D$. melanogaster Bologna population was larger than in the tropical populations. Interspe-

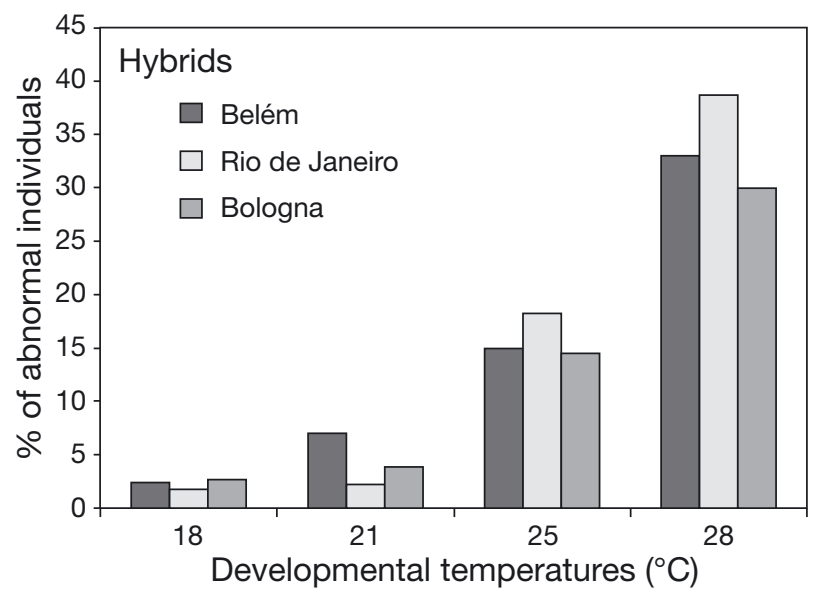

Fig. 2. Drosophila spp. Percentage of wing abnormalities in hybrids at the 4 different developmental temperatures: 18,21 , 25 and $28^{\circ} \mathrm{C}$. Belém: hybrids between $D$. melanogaster females from Belém and $D$. simulans males from Bologna; Rio de Janeiro: hybrids between $D$. melanogaster females from Rio de Janeiro and D. simulans males from Bologna; Bologna: hybrids between $D$. melanogaster females from Bologna and D. simulans males from Bologna cific hybrids had smaller wings than the respective $D$. melanogaster parent (except Belém hybrids at 18 and $21^{\circ} \mathrm{C}$ ). D. simulans wings were always smaller than the smallest wings in the $D$. melanogaster population (Belém) and quite similar to the hybrids in size. All the groups showed a decrease in wing size when the rearing temperature increased, with significant differences between groups $\left(F_{12,870}=11.8, \mathrm{p}<0.001\right)$.

Fig. $3 \mathrm{~b}$ shows the regression lines between midparent and hybrid centroid size over the 4 temperatures. The 3 hybrid lines differ in their intercepts giving evidence of a change of dominance in interspecific crosses $\left(F_{2,2}=30, \mathrm{p}=0.00075\right)$. Belém and Rio de Janeiro regression lines are very similar in slope. The regression coefficients are higher than 1 , indicating a greater plasticity of the hybrids. Bologna hybrids behaved differently, though with a relatively low level of significance $\left(F_{2,6}=4.74, \mathrm{p}=0.058\right)$; the regression coefficient is close to 1 , suggesting a similar response of midparents and hybrids.

\subsection{Wing shape variation}

The Species, Temperature and the interaction Species $\times$ Temperature effects in the MANOVA on the PC scores of the Procrustes coordinates were highly significant ( $p<0.001$ in all cases; Table 1). The population effect was also significant (Table 1), suggesting that wing shape also varies among Drosophila melanogaster populations and among hybrids with different genetic background. Separate analyses on populations or hybrids (i.e. 3 populations of $D$. melanogaster or 3 groups of hybrids) showed very high significant shape differences between populations and between hybrids ( $p<0.001$ in all cases, data not shown).

The discriminant analysis combined with canonical analysis provided a clear discrimination among groups. The first canonical axis, which accounted for $61 \%$ of the total variance (Fig. 4a), discriminated hybrids and parental species. Hybrids increased their wing shape divergence from parents at $25^{\circ} \mathrm{C}$ and even more at $28^{\circ} \mathrm{C}$, probably reflecting developmental noise more evident at higher temperatures (see also Fig. 2). Interestingly, the divergence was smaller in Bologna hybrids. The second canonical axis $(17 \%$ of the total variance) seemed to account only for the temperature effect (Fig. 4b).

\subsection{Allometric variation}

In order to test the effects of wing size on wing shape variation, an allometric correction was performed using a multivariate regression of the PC scores of the Pro- 

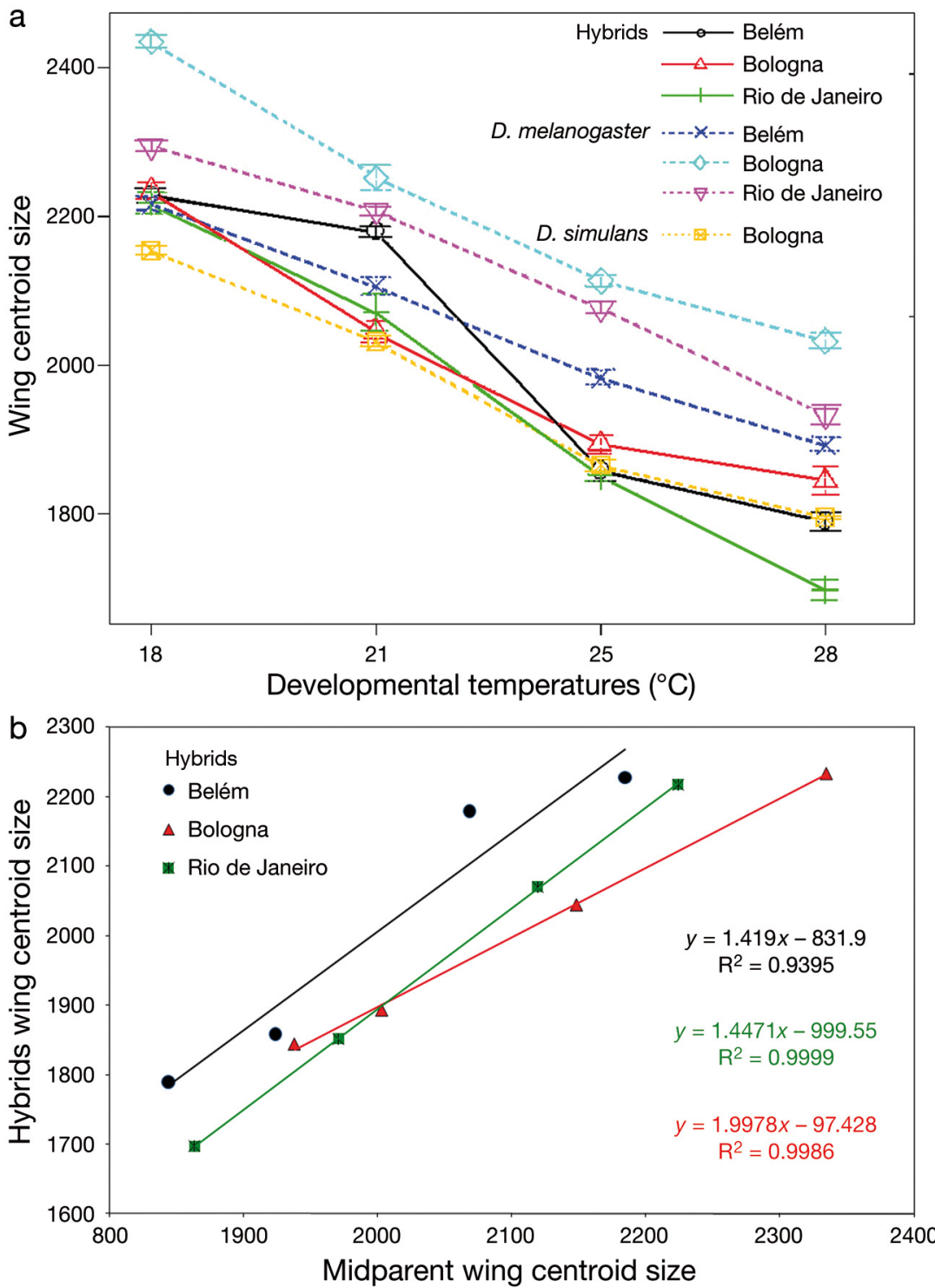

Fig. 3. Drosophila spp. (a) Mean wing centroid size $( \pm \mathrm{SE})$ of the 3 D. melanogaster populations, $D$. simulans and their hybrids at the 4 experimental temperatures: 18 , 21, 25 and $28^{\circ} \mathrm{C}$. (b) Relationship between centroid size of each hybrid and the respective midparent value at the 4 experimental temperatures. See Fig. 2 for description of hybrids crustes coordinates (dependent variables) on the wing centroid size (the independent variable). The multivariate regression coefficient of Procrustes coordinates on wing centroid size was highly significant $(r=0.842, \mathrm{p}<0.001)$, and a high amount of allometry in the Drosophila wing, which accounts for about $99 \%$ of the total shape variance, was found.

To test the effects of wing size on wing shape variation among species (i.e. Drosophila melanogaster, D. simulans and their hybrids) and temperature, a multivariate analysis of covariance (MANCOVA) was performed, with Species and Temperature as main effects and Population nested within Species and Temperature. All the effects in the MANCOVA were significant $(p<0.001$ in all cases, data not shown). The significant differences in the relationship between wing size and shape among groups show that the developmental allometric relationship (that is, how a wing changes its shape when the size varies) changes between temperatures and, more interestingly, between species or populations. The significant differences in slopes and intercepts show that non-allometric differences among groups are present.

It is interesting to note that the relationship between wing size and shape (allometry) changes when different geographic populations of Drosophila melanogaster (Bologna and Rio de Janeiro), but not different species coming from the same place (i.e. D. melanogaster and D. simulans collected in Bologna; Table 2), are considered.

Table 1. Results of the MANOVA with Temperature and Species as fixed effects and Population nested within Species and within temperature performed on the PC scores of the Procrustes coordinates of hybrids, D. melanogaster and D. simulans at the 4 experimental temperatures: $18,21,25$ and $28^{\circ} \mathrm{C}$. Num: numerator; Den: denominator; Pr: probability

\begin{tabular}{|lcccccc|}
\hline Source of variation & df & Pillai's trace & Approx $F$ & Num df & Den df & Pr $(>F)$ \\
\hline Intercept) & 1 & $1.45 \times 10^{-11}$ & $6.5 \times 10^{-10}$ & 19 & 852 & 1 \\
Species & 2 & 1.259 & 76.24 & 38 & 1706 & $<2 \times 10^{-16}$ \\
Temperature & 3 & 1.008 & 22.76 & 57 & 2562 & $<2 \times 10^{-16}$ \\
$\begin{array}{l}\text { Species } \times \text { Temperature } \\
\text { Populations within Species, }\end{array} \quad$ & 6 & 0.797 & 6.91 & 114 & 5142 & $<2 \times 10^{-16}$ \\
$\quad$ within Temperature & 16 & 1.749 & 5.6 & 304 & 13872 & $<2 \times 10^{-16}$ \\
Residuals & 870 & & & & & \\
\hline
\end{tabular}



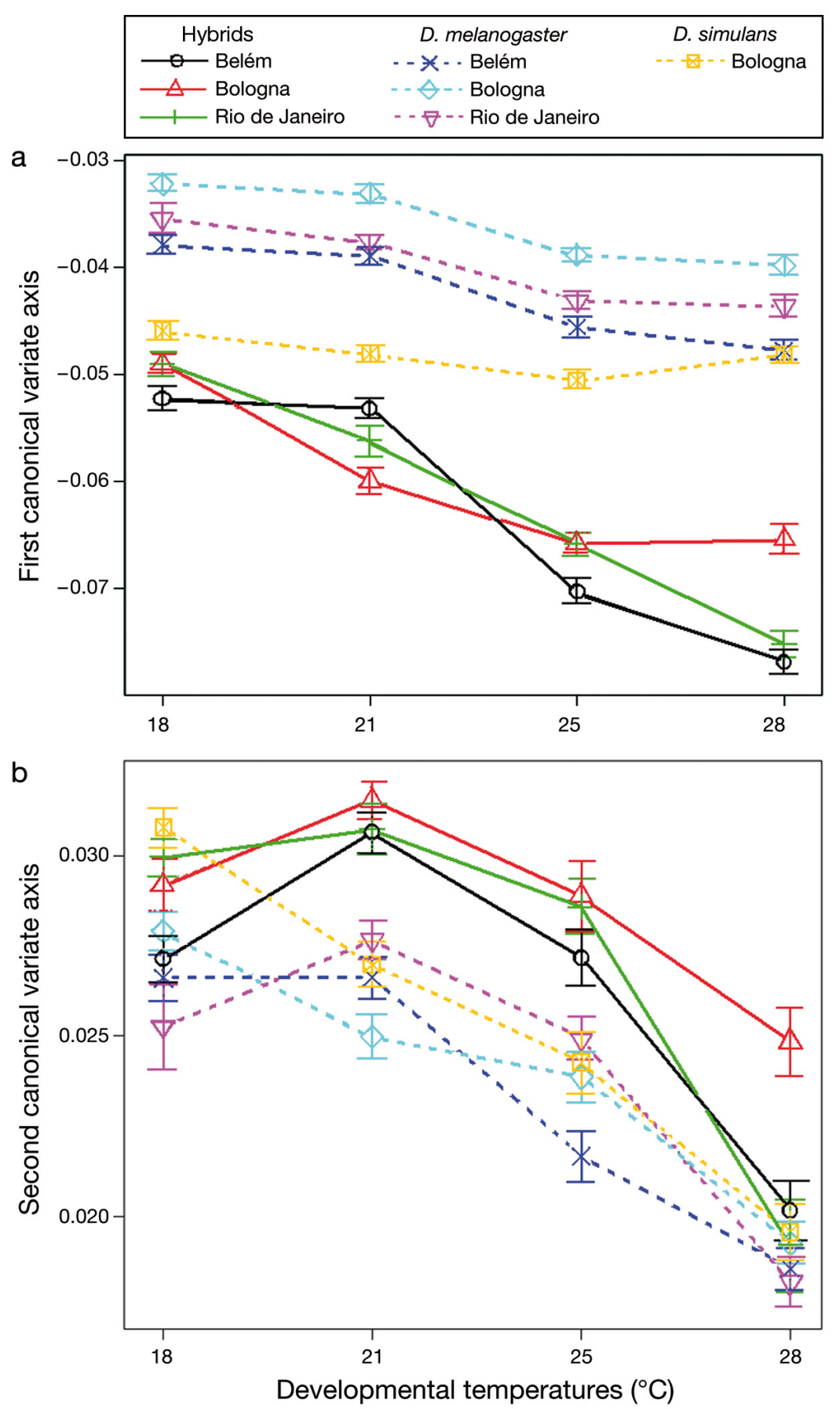

Fig. 4. Mean values ( $\pm \mathrm{SE}$ ) of (a) the first (whole shape variation) and (b) the second canonical plan computed from the canonical variate analysis on the PC scores of the Procrustes coordinates. See Fig. 2 for description of Drosophila hybrids tion, we explored how the past adaptive history of 2 related species, as well as of different populations of the same species, affects the plastic response to the environment.

\subsection{Morphological abnormalities}

The morphological abnormalities found in the hybrids were qualitatively similar to those reported by Markow \& Ricker (1991) and Rego et al. (2006). Wing abnormalities exponentially increased with increasing rearing temperature, giving evidence that hybrid development is seriously compromised at higher temperatures.

It has been shown that tropical populations tolerate high temperatures better than temperate ones (Trotta et al. 2006 and references therein), hence a hybrid with half a genetic background from a tropical Drosophila melanogaster might be more stable at high temperatures than a hybrid with a temperate genetic background. In spite of that, no significant differences among hybrids with different genetic backgrounds (i.e. Belém hybrids, Bologna hybrids and Rio de Janeiro hybrids) were found. The results indicate that buffer mechanisms that stabilize the development against genetic perturbations (breaking of the genomic coadaptation) are independent from those involved in the adaptations to climate conditions. However, Bologna hybrids (Fig. 2) showed a slightly lower percentage of abnormalities at $28^{\circ} \mathrm{C}$ (even if not significant) compared to the other hybrids. Since the parents came from the same geographic location, similar environmental buffering mechanisms could be shared between species, which would account for the more stable hybrids.

\section{DISCUSSION}

We investigated the phenotypic plasticity of wing size and shape in Drosophila melanogaster, D. simulans and their interspecific hybrids. With the aim to provide insight into the evolution of the norm of reac-

\subsection{Size variation}

Drosophila melanogaster exhibits numerous genetic body size differences between tropical and temperate populations (David \& Capy 1988, Gilchrist \& Partridge 1999, David et al. 2004). The adaptive significance of 
Table 2. MANCOVAs with Temperature and Populations (Drosophila melanogaster from Bologna and D. melanogaster from Rio de Janeiro) and with Temperature and Species (D. melanogaster and $D$. simulans from Bologna) as main effects on the global shape values covaried for wing centroid size. Num: numerator; Den: denominator; Pr: probability

\begin{tabular}{|c|c|c|c|c|c|c|c|c|c|c|c|}
\hline \multirow{2}{*}{ Source of variation } & \multirow{2}{*}{ df } & \multicolumn{5}{|c|}{ D. melanogaster populations } & \multicolumn{5}{|c|}{ Bologna D. melanogaster and D. simulans } \\
\hline & & Pillai & $\begin{array}{l}\text { Approx } \\
F\end{array}$ & $\begin{array}{c}\text { Num } \\
\text { df }\end{array}$ & $\begin{array}{c}\text { Den } \\
\text { df }\end{array}$ & $\operatorname{Pr}(>F)$ & Pillai & $\begin{array}{l}\text { Approx } \\
\text { F }\end{array}$ & $\underset{\mathrm{df}}{\mathrm{Num}}$ & $\begin{array}{c}\text { Den } \\
\text { df }\end{array}$ & $\operatorname{Pr}(>F)$ \\
\hline Size-shape regression & 1 & 0.776 & 37.1 & 19 & 203 & $<2.2 \times 10^{-16}$ & 0.863 & 65.4 & 19 & 198 & $<2.2 \times 10^{-16}$ \\
\hline Among Groups (intercepts) & 1 & 0.603 & 16.24 & 19 & 203 & $<2.2 \times 10^{-16}$ & 0.753 & 31.72 & 19 & 198 & $<2.2 \times 10^{-16}$ \\
\hline Among Temperatures (intercepts) & 3 & 1.250 & 7.71 & 57 & 615 & $<2.2 \times 10^{-16}$ & 1.078 & 5.91 & 57 & 600 & $<2.2 \times 10^{-16}$ \\
\hline Slopes among Groups & 1 & 0.333 & 5.34 & 19 & 203 & $1.99 \times 10^{-10}$ & 0.531 & 11.78 & 19 & 198 & $<2.2 \times 10^{-16}$ \\
\hline Slopes among Temperatures & 3 & 0.496 & 2.14 & 57 & 615 & $6.37 \times 10^{-6}$ & 0.716 & 3.3 & 57 & 600 & $2.52 \times 10^{-13}$ \\
\hline $\begin{array}{l}\text { Among Temperatures and } \\
\text { Groups (intercepts) }\end{array}$ & 3 & 0.821 & 4.07 & 57 & 615 & $<2.2 \times 10^{-16}$ & 0.366 & 1.46 & 57 & 600 & 0.018 \\
\hline $\begin{array}{l}\text { Slopes among Temperatures } \\
\text { and Groups }\end{array}$ & 3 & 0.547 & 2.41 & 57 & 615 & $1.54 \times 10^{-7}$ & 0.386 & 1.55 & 57 & 600 & 0.0072 \\
\hline Residuals & $221 / 216$ & & & & & & & & & & \\
\hline
\end{tabular}

these differences has been well described and interpreted as a response to the ambient temperature (Anderson 1973, Cavicchi et al. 1989, Partridge et al. 1994).

We have found that differences between the populations of Drosophila melanogaster, considered over the whole thermal range, were not clearly transmitted to the interspecific hybrids and, in this respect, genes for size in the 2 species seemed to not cooperate in an additive way (but see David et al. 2002). Hybrids were always smaller than the midparent. Because D. simulans is generally smaller than D. melanogaster (Capy et al. 1993, Gilchrist \& Partridge 1999, present study), the easiest formal interpretation is that D. simulans genes are somehow dominant (Moreteau et al. 1995). In other words, allelic interactions exist at the same loci. The complete data set points, however, to the more general interpretation of an F1 breakdown, probably due to deleterious epistatic gene interactions as shown, for example, in viability studies (e.g. Coyne \& Orr 1998). Hybrid breakdown may be observed in F1 or F2 generations as a consequence of either an interspecific or an intraspecific cross (Dobzhansky et al. 1977), resulting in a smaller size. In conclusion, hybrid breakdown has a strong effect on body size (smaller individuals), which was particularly evident at $28^{\circ} \mathrm{C}$.

\subsection{Phenotypic plasticity of wing size}

Apart from body size, the phenotypic plasticity of different Drosophila melanogaster populations seems to have also changed. D. melanogaster is a species of Afrotropical origin and climatic adaptation has occurred from tropical towards temperate climates (Lachaise et al. 1986). During the colonisation of temperate continents, adaptation has not only produced bigger flies, but also a shift in phenotypic plasticity: the maximum size is observed at a lower temperature in temperate populations (Trotta et al. 2006).

In the present study, wing size plasticity of hybrids seems to be higher than parental species in Belém and Rio de Janeiro crosses. However, given the strong size reduction at higher temperatures due to hybrid breakdown, it is possible that hybrid plasticity is not an 'adaptive' plasticity, but rather a side effect of a decanalized and impaired development. It is interesting to note the wing plasticity of Bologna hybrids (Fig. 3b) is the same as that of the parental species. Once again, as the 2 species share the same selective environment, they would have been subjected to the same plasticity selection so that a breakdown of the plastic response is avoided in hybrids.

\subsection{Wing shape variation}

The results of the present study show that wing shape is typical of each species, population and temperature. Moreover, there are wing shape differences in hybrids at different rearing temperatures. At 18 and $21^{\circ} \mathrm{C}$, wing shape plasticity in hybrids is similar to that of the 2 species, but the differences drastically increase at 25 and $28^{\circ} \mathrm{C}$ (Fig. 4a). It has been fully discussed that the development of hybrids is seriously compromised, especially at higher temperatures. The only possible conclusion is that, unlike body size, strong wing shape variations reflect strong developmental perturbations.

\subsection{Allometric variation}

The correlation between size and shape gives information on the links between the developmental machinery and the variation of a biological form. Considering shape as a univariate trait, the significant dif- 
ferences in slopes and intercepts among groups found in the MANCOVA indicate that the developmental allometric relationship between size and shape (that is, how a wing changes its shape when the size varies) changes among temperatures and among species. We can conclude that wing development is differently regulated in the 2 species and can be altered by natural selection.

Interestingly, the relationship between size and shape changes between populations of the same species of different geographic origin (Drosophila melanogaster, Bologna and Rio de Janeiro), but only slightly between the 2 species with the same geographic origin ( $D$. melanogaster and. D. simulans from Bologna; Table 2). These data support the hypothesis that the developmental allometric relationship between wing size and wing shape (i.e. the developmental machinery) has, under environmental selection, a similar impact on the 2 species.

Acknowledgements. We thank N. Torboli for her useful advice on hybrids and J. R. David for providing the Brazilian flies. Furthermore, we thank 2 anonymous reviewers for suggestions, and the European Science Foundation (ESF) ThermAdapt program.

\section{LITERATURE CITED}

Anderson WW (1973) Genetic divergence in body size among experimental populations of Drosophila pseudoobscura kept at different temperatures. Evolution 27:278-284

Bookstein FL (1991) Morphometric tools for landmark data: geometry and biology. Cambridge University Press, Cambridge

Braidotti G, Barlow DP (1997) Identification of a male meiosisspecific gene, Tcte2, which is differentially spliced in species that form sterile hybrids with laboratory mice and deleted in $\mathrm{t}$ chromosomes showing meiotic drive. Dev Biol 86:85-99

Calder WA (1984) Size, function and life history. Harvard University Press, Cambridge, MA

Capy P, Gibert P (2004) Drosophila melanogaster, Drosophila simulans: so similar yet so different. Genetica 120:5-16

Capy P, Pla E, David JR (1993) Phenotypic and genetic variability of morphometrical traits in natural populations of Drosophila melanogaster and D. simulans. I. Geographic variations. Genet Sel Evol 25:517-536

Carson H, Templeton AR (1984) Genetic revolutions in relation to speciation phenomena: the founding of new populations. Annu Rev Ecol Syst 15:97-131

Cavicchi S, Guerra D, Giorgi G, Pezzoli MC (1985) Temperature-related divergence in experimental populations of Drosophila melanogaster. I. Genetic and developmental basis of wing size and shape variation. Genetics 109: 665-689

> Cavicchi S, Guerra D, Natali V, Pezzoli MC, Giorgi G (1989) Temperature related divergence in experimental populations of Drosophila melanogaster. II. Correlation between fitness and body dimensions. J Evol Biol 2:235-251

> Cavicchi S, Giorgi G, Natali V, Guerra D (1991) Temperaturerelated divergence in experimental populations of Droso- phila melanogaster. III. Fourier and centroid analysis of wing shape and relationship between shape variation and fitness. J Evol Biol 4:141-159

> Charlesworth B, Lande R, Slatkin M (1982) A neo-Darwinian commentary on macroevolution. Evolution 36:474-498

Coyne JA, Orr HA (1998) The evolutionary genetics of speciation. Philos Trans R Soc Lond B 353:287-305

David JR, Capy P (1988) Genetic variation of Drosophila melanogaster natural populations. Trends Genet 4:106-111

David JR, Gibert P, Pétavy G, Moreteau B (2002) Variable modes of inheritance of morphometrical traits in hybrids between Drosophila melanogaster and Drosophila simulans. Proc R Soc Lond B 269:127-135

> David JR, Allemand R, Capy P, Chakir M, Gibert P, Petavy G, Moreteau B (2004) Comparative life histories and ecophysiology of Drosophila melanogaster and D. simulans. Genetica 120:151-163

de Jong G (1995) Phenotypic plasticity as a product of selection in a variable environment. Am Nat 145:493-512

Dobzhansky T (1936) Studies on hybrid sterility. 11. Localization of sterility factors in Drosophila pseudoobscura hybrids. Genetics 21:113-135

Dobzhansky T, Ayala FJ, Stebbins GL, Valentine JW (1977) Evolution. Freeman, San Francisco, CA

Dryden IL, Mardia KV (1998) Statistical shape analysis. Wiley, Chichester

Gilchrist AS, Partridge L (1999) A comparison of the genetic basis of wing size divergence in three parallel body size clines of Drosophila melanogaster. Genetics 153:1775-1787

> Griffiths JA, Schiffer M, Hoffmann AA (2005) Clinal variation and laboratory adaptation in the rainforest species Drosophila birchii for stress resistance, wing size and wing shape and development time. J Evol Biol 18:213-222

> Haas H, Tolley KA (1998) Geographic variation of wing morphology in three Eurasian populations of the fruit fly, Drosophila lummei. J Zool 245:197-203

Hammer Ø, Harper DAT, Ryan PD (2001) PAST: paleontological statistic software package for education and data analysis. Paleontol Electronica 4:1-9

Hansen J, Sato M, Ruedy R, Lo K, Lea DW, Medina-Elizade M (2006) Global temperature change. Proc Natl Acad Sci USA 103:14288-14293

Imasheva AG, Bubli OA, Lazebny OE, Zhivotovsky LA (1995) Geographic differentiation in wing shape in Drosophila melanogaster. Genetica 96:303-306

Klingenberg CP, Barluenga M, Meyer A (2002) Shape analysis of symmetric structures: quantifying variation among individuals and asymmetry. Evolution 56:1909-1920

Lachaise D, David JR, Lemeunier F, Tsacas L, Ashburner M (1986) The reproductive relationships of Drosophila sechellia with Drosophila mauritiana, Drosophila simulans and Drosophila melanogaster from the Afrotropical region. Evolution 40:262-271

> Markow TA, Ricker JP (1991) Developmental stability in hybrids between the sibling species pair, Drosophila melanogaster and Drosophila simulans. Genetica 84:115-121

- Matos M, Avelar T (2001) Adaptation to the laboratory: comments on Sgrò and Partridge. Am Nat 158:655-656

> Michalak P, Noor MAF (2003) Genome-wide patterns of expression in Drosophila pure species and hybrid males. Mol Biol Evol 20:1070-1076

Moreteau B, Petavy G, Gibert P, Morin JP, Munoz A, David JR (1995) New discriminating traits between females of two sibling species: Drosophila melanogaster and D. simulans (Diptera, Drosophilidae). Ann Soc Entomol Fr 31:249-257

Muller HJ (1942) Isolating mechanisms, evolution, and temperature. Biol Symp 6:71-125 
Orr HA, Madden LD, Coyne JA, Goodwin R, Hawley RS (1997) The developmental genetics of hybrid inviability: a mitotic defect in Drosophila hybrids. Genetics 145:1031-1040

Partridge L, Farquhar M (1983) Lifetime mating success of male fruitflies (Drosophila melanogaster) is related to their size. Anim Behav 31:871-877

Partridge L, French V (1996) Thermal evolution of ectotherm body size: Why get big in the cold? In: Johnston IA, Bennet AF (eds) Animals and temperature: phenotypic and evolutionary adaptation. Cambridge University Press, Cambridge, p 265-296

Partridge L, Barrie B, Fowler K, French V (1994) Evolution and development of body size and cell size in Drosophila melanogaster in response to temperature. Evolution 48: 1269-1276

Penin X, Berge C, Baylac M (2002) Ontogenetic study of the skull in modern humans and the common chimpanzees: neotenic hypothesis reconsidered with a tridimensional Procrustes analysis. Am J Phys Anthropol 118:50-62

Peters RH (1983) The ecological implications of body size. Cambridge University Press, Cambridge

Price TD, Qvarnstrom A, Irwin DE (2003) The role of phenotypic plasticity in driving genetic evolution. Proc R Soc Lond B 270:1433-1440

R Core Development Team (2005) R: a language and environment for statistical computing. R Foundation for Statistical Computing, Vienna, available at www.R-project.org

Ranz JM, Namgyal K, Gibson G, Hartl DL (2004) Anomalies in the expression profile of interspecific hybrids of Drosophila simulans and Drosophila melanogaster. Genome Res 14:373-379

Rawson PD, Burton RS (2002) Functional coadaptation between cytochrome $c$ and cytochrome $c$ oxidase within allopatric populations of a marine copepod. Proc Natl Acad Sci USA 99:12955-12958

Reed SC, Reed EW (1948) Morphological differences and problems of speciation in Drosophila. Evolution 2:40-48

Rego C, Matos M, Santos M (2006) Symmetry breaking in interspecific Drosophila hybrids is not due to developmental noise. Evolution 60:746-761

Robertson FW (1957) Studies in quantitative inheritance. XI. Genetic and environmental correlation between body size and egg production in Drosophila melanogaster. Cold Spring Harb Symp Quant Biol 20:166-177

Roff DA (1992) The evolution of life histories: theory and analysis. Chapman and Hall, New York

Rohlf FJ, Marcus LF (1993) A revolution in morphometrics.
Trends Ecol Evol 8:129-132

Rohlf FJ, Slice DE (1990) Extensions of the Procrustes method for the optimal superimposition of landmarks. Syst Zool 39:40-59

Santos M, Fernández Iriarte P, Céspedes W, Balanyà J, Fontdevila A, Serra L (2004) Swift laboratory thermal evolution of wing shape (but not size) in Drosophila subobscura and its relationship with chromosomal inversion polymorphism. J Evol Biol 17:841-855

Scheiner SM (1993) Genetics and evolution of phenotypic plasticity. Annu Rev Ecol Syst 24:35-68

Scheiner SM, Lyman RF (1991) The genetic of phenotypic plasticity. II. Response to selection. J Evol Biol 4:95-107

Schmidt-Nielsen K (1983) Scaling: Why is animal size so important? Cambridge University Press, Cambridge

Serreze MC (2010) Understanding recent climate change. Conserv Biol 24:10-17

Slice DE, Bookstein FL, Marcus LF, Rolf FJ (1996) A glossary for geometric morphometrics. In: Marcus LF, Corti A, Loy A, Naylor GJP, Slice DE (eds) Advances in morphometrics, Vol 284. Plenum Press, New York, NY, p 531-551

Stearns SC (1989) The evolutionary significance of reaction norms. Bioscience 39:436-446

Sturtevant AH (1920) Genetic studies on Drosophila simulans. I. Introduction. Hybrids with Drosophila melanogaster. Genetics 5:488-500

> Sucena E, Delon I, Jones I, Payre F, Stern DL (2003) Regulatory evolution of shavenbaby/ovo underlies multiple cases of morphological parallelism. Nature 424:935-938

Tantawy AO, Vetukhiv MO (1960) Effects of size on fecundity, longevity and viability in populations of Drosophila pseudoobscura. Am Nat 94:395-403

Trotta V, Calboli FCF, Ziosi M, Guerra D, Pezzoli MC, David JR, Cavicchi S (2006) Thermal plasticity in Drosophila melanogaster: a comparison of geographic populations. BMC Evol Biol 6:67

Trotta V, Calboli FCF, Ziosi M, Cavicchi S (2007) Fitness variation in response to artificial selection for reduced cell area, cell number and wing area in natural populations of Drosophila melanogaster. BMC Evol Biol 7(Suppl 2):S10

West-Eberhard MJ (2003) Developmental plasticity and evolution. Oxford University Press, Oxford

West-Eberhard MJ (2005) Developmental plasticity and the origin of species differences. Proc Natl Acad Sci USA 102(Suppl 1):6543-6549

Wilkinson GS (1987) Equilibrium analysis of sexual selection in Drosophila melanogaster. Evolution 41:11-21

Proofs received from author(s): June 28, 2010 